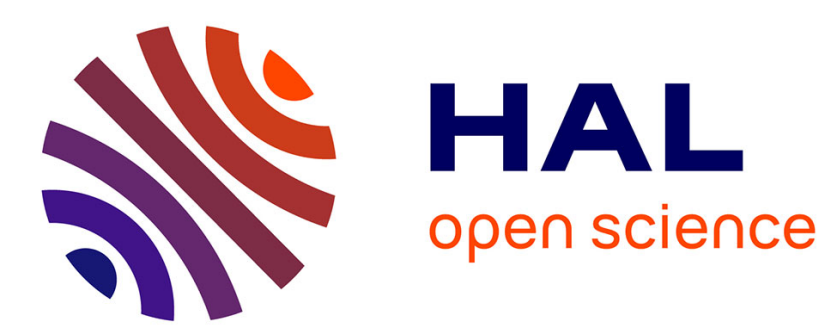

\title{
Photoacoustic plasmon resonance spectra of Langmuir-Blodgett films
}

\author{
Yuchao Jiang, S. Zhang, F. Qian, H. Shao
}

\section{To cite this version:}

Yuchao Jiang, S. Zhang, F. Qian, H. Shao. Photoacoustic plasmon resonance spectra of Langmuir-Blodgett films. Journal de Physique IV Proceedings, 1994, 04 (C7), pp.C7-35-C7-38. 10.1051/jp4:1994709 . jpa-00253150

\section{HAL Id: jpa-00253150 https://hal.science/jpa-00253150}

Submitted on 1 Jan 1994

HAL is a multi-disciplinary open access archive for the deposit and dissemination of scientific research documents, whether they are published or not. The documents may come from teaching and research institutions in France or abroad, or from public or private research centers.
L'archive ouverte pluridisciplinaire HAL, est destinée au dépôt et à la diffusion de documents scientifiques de niveau recherche, publiés ou non, émanant des établissements d'enseignement et de recherche français ou étrangers, des laboratoires publics ou privés. 


\title{
Photoacoustic plasmon resonance spectra of Langmuir-Blodgett films
}

\author{
Y.S. Jiang, S.Y. Zhang, F. Qian* and H.P. Shao \\ Institute of Acoustics and Lab. of Modern Acoustics, Nanjing University, Nanjing 210093, China \\ * Dept. of Physics, Southeast University, Nanjing 210018, China
}

\begin{abstract}
The surface plasmon spectra of Langmuir-Blodgett (LB) films have been investigated by combining photoacoustic technique with resonant attenuated total reflection spectroscopy. By this technique, the experimental PA angular spectra of cadmium stearate LB films have been obtained. According to the electromagnetic theory and considering the anisotropic properties of LB films, as well as based on the experimental photoacoustic plasma resonance curves, we have determined the optical constants and thicknesses of the films by using numerical optimization method.
\end{abstract}

\section{INTRODUCTION}

Langmuir-Blodgett (LB) films have potential applications in the fields of optical devices and molecular electronics owing to their highly orderly molecular structures[1]. Great attention has been concentrated on the studies of Langmuir-Blodgett films[2]. In this paper we describe the characterization of the optical properties of the multilayers composed of cadmium stearate by photoacoustic (PA) technique combining with the surface plasma oscillation (SPO) spectra[3]. The SPO technique is a precision instrument for characterizing thin films. On the other hand, the PA technique[4] has the advantages of higher sensitivity and simpler optical system. Thus the refractive indices and thicknesses of cadmium stearate LB films deposited on the silver films, which are evaporated on the bottom of a prism, can be sensitively and successfully determined by combining the PA with the SPO technique.

Since LB films consist of an array of monomolecular layers, in which molecules are in good orientation, the films have been found to be a kind of uniaxial anisotropic films with the optical axis perpendicular to the film surface[5], thus, at least three unknown parameters, the ordinary refractive indices, extraordinary refractive indices and the thicknesses of the films must be determined. However, generally there is only one PA resonance absorption peak on the PA angular spectrum using p-polarized incident light measurement because the films are very thin. Therefore, the problem of calculating the parameters of LB films from the resonant angle position becomes very delicate. We have applied a constrained numerical optimization method--complex method[6] to solve this problem. By substituting the optimized values of the parameters of the LB films into the theoretical expressions of the PA signals, we can get the theoretical curves which are in good agreement with experiment. 


\section{EXPERIMENT}

The LB films are fabricated by using the conventional Langmuir-Blodgett technique which has been described elsewhere in detail[1]. The conditions of monolayer deposition for LB films in our work are as follows: the stearate acid is dissolved in chloroform to the molar concentration of $3 \times 10^{-3} \mathrm{M}$ and then spread onto the surface of an aqueous subphase containing approximately $4 \times 10^{-4} \mathrm{M} \mathrm{CdCl}_{2}$ for forming the cadmium stearate monolayer. The surface pressure chosen for depositing onto a silver film is $35 \mathrm{mN} / \mathrm{m}$. The silver film with the thickness $57.5 \mathrm{~nm}$ is evaporated onto the bottom of BK-7 glass prism with refractive index $\mathrm{n}_{0}=1.523$. The cad-

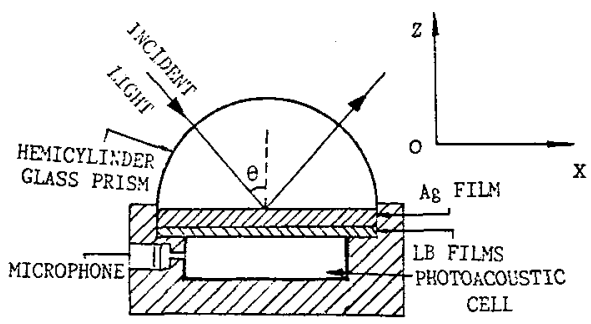

Fig.1. Schematic cross-sectional view of the ATR photo-plasmon coupler equipped with a photomacoustic cell mium stearate LB films are fabricated in the most common deposition mode (Y-type), i.e., the amphiphilic molecules stack in a head-to-head and tail-to-tail configuration.

The cross-section of experimental setup for PA signal detection is shown in Fig.1. A p-polarized argon ion laser beam with wavelength $488 \mathrm{~nm}$ modulated by a chopper at frequency of $179 \mathrm{~Hz}$ illuminates the sample through the hemicylindrical prism. When the incident angle $\theta$ is larger than the critical angle, total reflection occurs and the surface plasmon wave is excited in the thin silver film. The dispersion characteristics of the plasmon wave are very sensitive to the properties of the dielectric overlayers. In particular, the small changes in the optical properties of the dielectric layer are readily detected by the PA technique. In the PA system, a miniature electret microphone attached to a airfilled cavity, which is confined with the prism, is used for receiving the PA signal. The points in Fig.2 are the experimental results obtained by the PA SPO for cadmium stearate LB films composed of 0,3 , 7 and 11 monolayers marked with a,b,c and

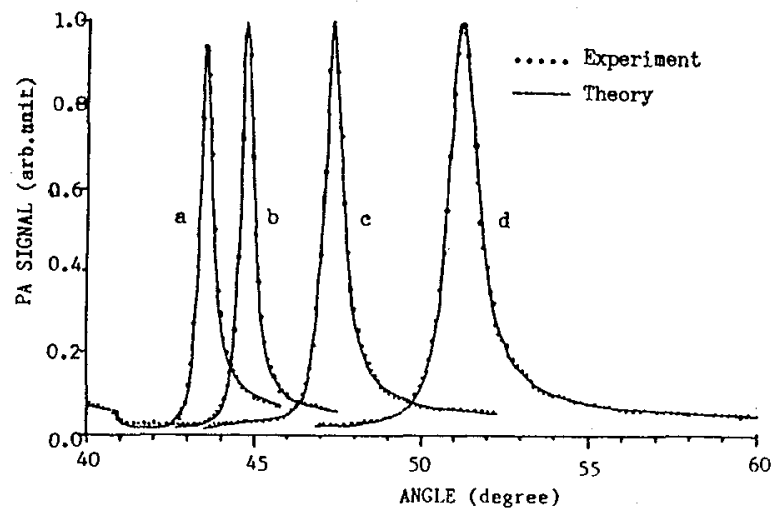

Fig.2. PA- $\theta$ curves of the silver films covered with (a) $0,(b) 3$, (c) 7 and (d) 11 monolayers of
cadmium stearate LB films $\mathrm{d}$ respectively. Then, the refractive indices and the thicknesses of the LB films can be determined by electromagnetic theory and optimization method based the resonance angular position $\theta_{\mathrm{r}}$.

\section{THEORY}

We consider the four media system composed of prism, silver film, LB films and air, and let the incident plane be the plane of XOZ(see Fig.1). The magnetic field has only y component

$$
H_{y}{ }^{(j)}=A_{j} \exp ^{i\left(\alpha x-\beta_{j} z\right)}+B_{j} \exp ^{-i\left(\alpha x+\beta_{j} z\right)} \quad(j=1,2,3,4)
$$

where ${ }^{\prime} \alpha=\mathrm{kn}_{\mathrm{j}} \sin \theta_{\mathrm{j}}, \quad \boldsymbol{B}_{\mathrm{j}}=\mathrm{kn}_{\mathrm{j}} \cos \theta_{\mathrm{j}}, \mathrm{j}=1,2,3,4$ represent the prism, silver film, LB films and air, respectively. $k$ is the optical wave vector of free space. $n_{j}$ is the refractive index of the $j$ th layer. According to Maxwell's equation, we have the $\mathrm{x}$ and $\mathrm{z}$ components of the electric field: 


$$
\begin{array}{ll}
E_{x}^{j}=-\left(\frac{1}{k n_{j}^{2}}\right)\left(\frac{\partial}{\partial z}\right) H_{y}^{j} & (j=1,2,3,4) \\
E_{z}^{j}=\left(\frac{1}{k n_{j}^{2}}\right)\left(\frac{\partial}{\partial z}\right) H_{y}^{j} & (j=1,2,3,4)
\end{array}
$$

If we apply the condition of continuity of tangential component of the field at the boundary, we obtain the overall reflection of the four layer model system

$$
R=\frac{r_{12}+I_{23} \exp \left(-2 i \delta_{2}\right) I_{34} \exp \left[-2 i\left(\delta_{2}+\delta_{3}\right)\right]+r_{12} r_{23} r_{34} \exp \left(-2 i \delta_{3}\right)}{1+I_{12} r_{23} \exp \left(-2 i \delta_{3}\right)+I_{12} r_{34} \exp \left[-2 i\left(\delta_{2}+\delta_{3}\right)\right]+r_{23} r_{34} \exp \left(-2 i \delta_{3}\right)}
$$

where

$$
r_{i j}=\frac{n_{j}^{2} k_{i}-n_{i}^{2} k_{j}}{n_{j}^{2} k_{i}+n_{i}^{2} k_{j}}
$$

and $\delta_{\mathrm{i}}=\mathrm{k}_{\mathrm{i}} \mathrm{d}_{\mathrm{i}}, \mathrm{k}_{\mathrm{i}}=(\omega / \mathrm{c})\left(\mathrm{n}_{\mathrm{i}}^{2}-\mathrm{n}_{1}^{2} \sin ^{2} \theta\right)^{1 / 2}, \mathrm{~d}_{\mathrm{i}}$ is the thickness of the $\mathrm{i}$-th layer. It is assumed that the LB film has an uniaxial symmetry with the optic axis perpendicular to the film surface as the assumption made by Engelsen[5]. Then the refractive index $n_{3}$ of an uniaxial crystal for p-polarized propagating light is

$$
n_{3}=\frac{\sqrt{n_{30}{ }^{2} n_{3 e}{ }^{2}+\left(n_{3 e}{ }^{2}-n_{30}{ }^{2}\right) n_{1}{ }^{2} \sin ^{2} \theta}}{n_{3 e}}
$$

where $n_{30}, n_{3 e}$ correspond to the refractive indices of the ordinary ray and extraordinary ray in LB films, respectively. Then the PA signal received by the electret microphone can be expressed as

$$
V_{P A}=\eta\left(1-R R^{*}\right)
$$

where $\mathrm{R}^{*}$ is the complex conjugate of $\mathrm{R}$ and $\eta$ is the transformation coefficient of the light to sound. From Eq.(4) to Eq.(7), we can see that the PA signal changes with the incident angle, which is determined by the thickness $d_{3}$ and optical constants $n_{30}, n_{3 e}$ of the LB film. Based on the defined parameters $n_{1}, n_{2}, d_{2}$ and $n_{4}$, we can calculate the $V_{P A}-\theta$ curves as the functions of $n_{30}, n_{3 e}$ and $d_{3}$.

When the incident angle $\theta$ satisfies the match condition between the photon momenta in prism and the plasmon surface polariton, the PA signal will achieve a strong enhancement, i.e., the PA resonance peak will appear in the spectrum. The match condition is

$$
\frac{2 \pi}{\lambda} \sin \theta_{r}=\operatorname{Re}\left(k_{s}\right)
$$

where $k_{s}$ is the wavevector of the surface plasma wave, the angular position $\theta_{\mathrm{r}}$ is of the resonant maximum, which depends on the various parameters $\left(n_{30}, n_{3 e}, d_{3}\right)$ of the LB films. Eq. (8) can be regarded as the constrained condition for $\mathrm{V}_{\mathrm{PA}}=\left(\mathrm{V}_{\mathrm{PA}_{\mathrm{A}}}\right)_{\max }$. Then the measurement of the angular position $\theta_{\mathrm{r}}$ of the absorption peak can provide the information of the parameters.

\section{NUMERICAL CALCULATION RESULTS AND DISCUSSION}

In order to determine the values of $n_{30}, n_{3 e}, d_{3}$ simultaneously, while only one resonant peak exists in the $\mathrm{V}_{\mathrm{PA}}-\theta$ curve as in our experiment, we present a numerical optimization method to solve the problem. 
Let $n_{30}, n_{3 e}$, and $d_{3}$ be given by 3-dimensional vector $X$, and $f(X)=V_{P A}\left(n_{30}, n_{3 e}, d_{3}, \theta_{r}\right)$ be an object function at a domain $\mathbf{D}$ determined by the general knowledge. The domain $\mathbf{D}$ and Eq.(8) can be regarded as the constrained conditions of $f(\mathbf{X})=[f(\mathbf{X})]_{\max }$. Therefore, the problem is that choosing the proper values of $n_{30}, n_{3 e}$, and $d_{3}(i . e$. three components of $X$ ) under constraining of the domain $\mathbf{D}$ and Eq. (8) makes the $\mathrm{f}(\mathbf{X})$ to be maximum. This is a typical constrained optimization problem. We use a complex method to the problem. The details of the method were outlined in reference[6].

The given parameters of the layered system are: the $d_{2}=57.5 \mathrm{~nm}$ of the silver film is determined by fitting the theoretical $\theta_{\mathrm{r}}$ to the experimental results of the bare silver, the refractive index of silver $\mathrm{n}_{2}=0.05+3.041 \mathrm{i}$ is taken from ref. [7]. By substituting the parameters and $\theta_{\mathrm{s}}$ obtained from experimental curves into Eq.(7) and according to algorithm of complex method, we obtained $n_{30}, n_{3 e}, d_{3}$ for different thicknesses of LB films simultaneously. They are listed in table 1 . We can see that the parameters in the films with three different thicknesses of LB films are obtained with the errors less than $1.3 \%$ and are also approximately identical to reference[8]. By substituting the parameters in table 1 into Eq. (4)--(7), we calculate the theoretical PA spectra shown by solid lines in Fig. 2. From Fig.2, we can see that the results of theory and experiment are in good agreement, and the resonance position shift to the larger

Table 1: Optical constants and thicknesses of cadmium stearate LB films

\begin{tabular}{|c|c|c|c|c|}
\hline $\begin{array}{c}\text { Number } \\
\text { of } \\
\text { Monolayer }\end{array}$ & $\mathrm{n}_{30}$ & $\mathrm{n}_{3 \mathrm{e}}$ & $\mathrm{d}_{3}$ & $\begin{array}{c}\text { Average } \\
\text { Thickness } \\
\text { of } \\
\text { Monolayer } \\
(\mathrm{nm})\end{array}$ \\
\hline 3 & 1.53 & 1.54 & 7.53 & 2.51 \\
\hline 7 & 1.53 & 1.57 & 17.67 & 2.52 \\
\hline 11 & 1.51 & 1.54 & 27.48 & 2.50 \\
\hline
\end{tabular}
incident angles with the increased thicknesses of $\mathrm{LB}$ films. For example, one monolayer thickness $(\approx 25 \AA)$ of the LB films may cause the resonance angle shift at least $0.4^{\circ}$. Since the angular resolution of our experimental apparatus is better than $0.05^{\circ}$, therefore, the thickness changes of LB films can be detected even only one monolayer.

In conclusion, we have developed the PA SPO technique which has the common advantages of simpler optical system and higher sensitivity than general optical system. Besides, we have also applied the constrained optimized complex method for determining the optical constants and thicknesses of LB films simultaneously. The complex method makes it much easier to get the results than other general algebraic methods. Finally, it must be pointed out that the PA SPO technique and the complex method can also be used for characterizing other materials with thin layered structures.

\section{References}

[1] Roberts G.G., Adv. Phys. 34 (1985) 475-512.

[2] Pitt C.W. and Walpita L.M., Thin Solid Films 68 (1980) 33-45.

[3] Negm S. and Talaat H., Photoacoustic and Photothermal Phenomena II. Eds, Murphy J., Madachlan Spicer J.W., Aamodt L.C. and Royce B.S.H., (Springer Series in Optical Sciences 62,1989) pp.120-123.

[4] Qiu S.Y., Zhang S.Y., Hu C.N. and Wei L.H., J. Appl. Sci. 4 (1986) 207-211 (in Chinese)

[5] Engelson D.D., J.Opt.Soc.Am. 61 (1980) 1460-1466.

[6] Richardson J.A. and Kuester J.L., Communications of ACM 16 (1973) 487-489.

[7] Johnson P.B. and Christy R.W., Phys. Rev. B 6 (1972) 4370-4379.

[8] Matsuda A., Sugi M., Fukui T. and Bizima S., J. Appl. Phys. 48 (1977) 771-774. 